
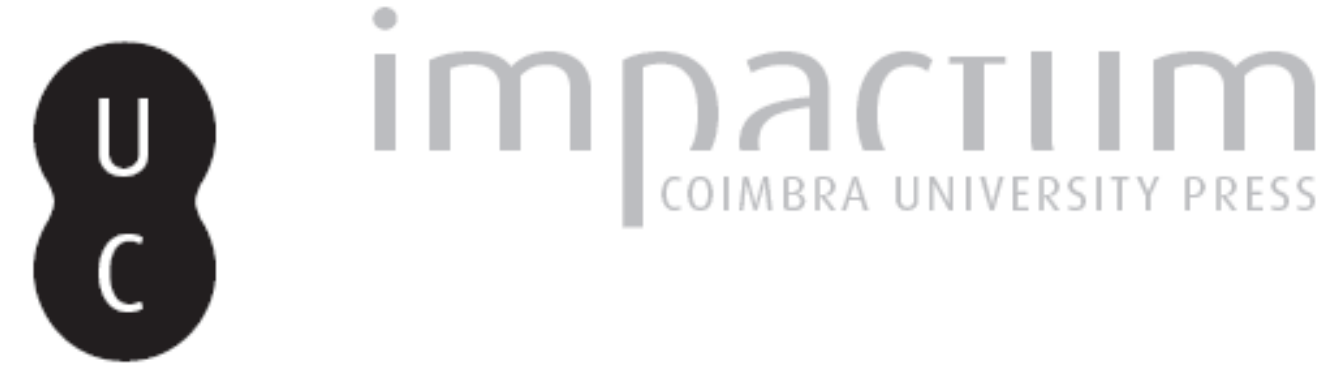

\title{
Utilização de tabelas como referência na avaliação do dano corporal: análise de três grupos profissionais brasileiros
}

Autor(es): $\quad$ Verçosa, C.; Zanon, M.; Kanamura, M.; Corte-Real, A.; Melani, R.

Publicado por: Imprensa da Universidade de Coimbra

URL

persistente:

URI:http://hdl.handle.net/10316.2/33261

DOI:

DOI:http://dx.doi.org/10.14195/1647-8630_23_4

Accessed : $\quad$ 26-Apr-2023 15:16:36

A navegação consulta e descarregamento dos títulos inseridos nas Bibliotecas Digitais UC Digitalis, UC Pombalina e UC Impactum, pressupõem a aceitação plena e sem reservas dos Termos e Condições de Uso destas Bibliotecas Digitais, disponíveis em https://digitalis.uc.pt/pt-pt/termos.

Conforme exposto nos referidos Termos e Condições de Uso, o descarregamento de títulos de acesso restrito requer uma licença válida de autorização devendo o utilizador aceder ao(s) documento(s) a partir de um endereço de IP da instituição detentora da supramencionada licença.

Ao utilizador é apenas permitido o descarregamento para uso pessoal, pelo que o emprego do(s) título(s) descarregado(s) para outro fim, designadamente comercial, carece de autorização do respetivo autor ou editor da obra.

Na medida em que todas as obras da UC Digitalis se encontram protegidas pelo Código do Direito de Autor e Direitos Conexos e demais legislação aplicável, toda a cópia, parcial ou total, deste documento, nos casos em que é legalmente admitida, deverá conter ou fazer-se acompanhar por este aviso.

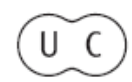


REVISTA PORTUGUESA

$\stackrel{\infty}{\cdots}$

$\stackrel{2}{i}$

$\dot{\bar{x}}$

$\bar{x}_{\bar{x}}$

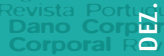

Oeno dorporal Revista Portuguesta do Dano Corporal Revista Portuguens do Dano Corporal

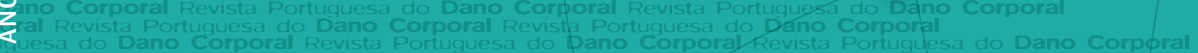

Rvista Portuguesa do Dano Corporal Revista Portuguesa do Dano Corporal Revista Portuguesa do pang Coporal

NPortuguesa do Dano Corporal Revista Portuguesd do Dano Corporal

Silo

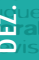

\section{APADAC}

ASSOCIAÇÃO PORTUGUESA

DE AVALIAÇÃO

DO DANO CORPORAL

INSTITUTO NACIONAL

DE MEDICINA LEGAL, I.P.

DELEGAÇÃO DO CENTRO 


\section{Utilização de tabelas como referência na avaliação do dano corporal. Análise de três grupos profissionais brasileiros}

C. Verçosa(1), M. Zanon(2), M. Kanamura(3), A. Corte-Real (4), R. Melani(5)

\section{INTRODUÇÃO}

A utilização de tabelas como referência para avaliação do dano corporal, em várias vertentes do direito: civil, penal e trabalho, é o elemento essencial no estabelecimento da uniformidade de critérios que possibilitam a clareza no entendimento entre peritos e juristas, bem como esclarecendo ao sinistrado/ vítima a valorização das suas sequelas (Corte-Real, 2003; Caldas, Magalhães et al., 2008).

A utilização de uma referência permite abordagens uniformes por peritos diferentes, conduzindo a conclusões comuns perante perfis de sequelas semelhantes, contribuindo para uma harmonização dos métodos de avaliação do dano corporal (Vieira e Quintero, 2008).

Embora exista uma tabela utilizada no Brasil, Tabela de Invalidez Total ou Parcial por Acidente (Susep) (tabela 1 e anexo 1), tal tabela não contempla plenamente todos os possíveis danos que podem envolver o campo odontológico, como fraturas, comprometimento de tecido periodontal e os respectivos reflexos na oclusão dentária, nomeadamente se comparada com a Tabela Nacional de Avaliação de Incapacidades Permanentes em Direito Civil (Decreto-Lei n⿳352/2007 de 23 de Outubro 2007) (tabela 2), que perspectiva um número maior de sequelas.

\footnotetext{
1 Faculdade de Odontologia, Universidade de São Paulo, Brasil

2 Faculdade de Odontologia, Universidade de São Paulo, Brasil

3 Faculdade de Odontologia, Universidade de São Paulo, Brasil

4 Faculdade de Medicina, Universidade de Coimbra, Portugal

5 Faculdade de Odontologia, Universidade de São Paulo, Brasil
} 
Tabela 1 - Algumas sequelas e respectivas percentagens de incapacidade consideradas na Tabela de Invalidez Total ou Parcial por Acidente (SUSEP)

\begin{tabular}{ll}
\hline \multicolumn{2}{c}{$\quad$ Parcial - Diversos } \\
\hline Perda total da visão de um olho & $30 \%$ \\
Perda total da visão de um olho quando o segurado já não tivera outra vista & $70 \%$ \\
Surdez total e incurável de ambos os ouvidos & $40 \%$ \\
Surdez total e incurável de um dos ouvidos & $20 \%$ \\
Mudez incurável & $50 \%$ \\
Fratura não consolidada do maxilar inferior & $20 \%$ \\
Imobilidade do segmento cervical da coluna vertebral & $20 \%$ \\
\hline Imobilidade do segmento toraco-lombo-sacro da coluna vertebral & $25 \%$ \\
\hline
\end{tabular}

Tabela 2 - Tabela Nacional de Avaliação de Incapacidades Permanentes em Direito Civil

\section{Estomatologia}

\begin{tabular}{|c|c|}
\hline $\begin{array}{l}\text { Edentação completa insusceptível de correção por prótese } \\
\text { (atendendo à repercussão sobre o estado geral) }\end{array}$ & 20 a 28 \\
\hline $\begin{array}{l}\text { Perda de dente insusceptível de correção por prótese: } \\
\text { Incisivo ou canino } \\
\text { Premolar ou molar }\end{array}$ & \\
\hline Disfunções mandibulares & 21 a 30 \\
\hline $\begin{array}{l}\text { Limitação da abertura bucal igual ou inferior a } 10 \mathrm{~mm} \\
\text { Limitação da abertura bucal entre } 10 \text { a } 30 \mathrm{~mm} \\
\text { Limitação da abertura entre } 31 \text { e } 40 \mathrm{~mm} \\
\text { (atendendo à bilateralidade, fenômenos dolorosos e perturbação da função) }\end{array}$ & 6 a 20 \\
\hline $\begin{array}{l}\text { Perturbação pós-traumática da oclusão dentária ou da articulação têmporo } \\
\text { mandibular } \\
\text { (segundo a repercussão sobre a mastigação, a fonação e as algias) }\end{array}$ & 2 a 10 \\
\hline $\begin{array}{l}\text { Amputação da parte móvel da língua } \\
\text { (tendo em consideração a repercussão sobre a palavra, a mastigação e a } \\
\text { deglutição,segundo a importância das perturbações) }\end{array}$ & 3 a 30 \\
\hline
\end{tabular}

O perito deve esclarecer a existência de uma sequela com seus respectivos aspectos anatômicos funcionais e psicológicos, tendo por objetivo estabelecer a justa relevância das consequências clínicas e sociais decorrentes do dano (Cardozo, 1994).

Neste trabalho, podemos considerar a necessidade de sistematização da avaliação dos danos corporais, no âmbito de uma apreciação odontológica englobada numa avaliação médico-legal.

Pretendemos avaliar o conhecimento, a experiência, a adequação das sequelas e respectivas pontuações, junto dos médicos, médicos dentistas e advogados. Questionamos, por fim, a introdução de uma tabela de avaliação médico-legal na prática pericial brasileira. 


\section{REVISÃO DA LITERATURA}

A tabela de quantificação de sequelas corporais surgiu tendo por objetivo valorizar a perda de incapacidade de ganho, estando intimamente ligada aos Acidentes de Trabalho. A primeira tabela portuguesa de avaliação dos danos corporais, de 1960, designada por Tabela Nacional de Incapacidades por Acidentes de Trabalho ou Doenças Profissionais (Decreto-Lei no 352/2007 de 23 de Outubro 2007) sofreu sucessivas atualizações até 2007, quando foi substituída pela atual tabela (Vieira e Quintero, 2008).

Em virtude da evolução tecnológica e dos riscos à integridade física e psicológica dos cidadãos foi relatado um número crescente de situações para avaliação de danos corporais. Deste modo surgiram os seguros obrigatórios de responsabilidade civil e a necessidade de valorizar ad integrum o indivíduo, cujas orientações, indevidamente executadas, tinham por base, e como única tabela, uma tabela orientada para a valorização no âmbito do direito do trabalho (Corte-Real, 2003; Vieira e Quintero, 2008).

Em 2007 entrou em vigor, em Portugal, a Tabela Nacional de Avaliação de Incapacidades Permanentes em Direito Civil, conjuntamente com uma nova atualização da Tabela Nacional de Incapacidades por Acidentes de Trabalho ou Doenças Profissionais (Decreto-Lei no 352/2007 de 23 de Outubro 2007). A tabela para o Direito Civil teve por base a Tabela Europeia para Avaliação do Dano Corporal, definindo um instrumento de medida de maior precisão e uniformização de critérios. Desta forma, facilita-se a avaliação das dificuldades para a realização das atividades da vida diária, simples ou complexas, e não apenas as relativas à vida laboral (Decreto-Lei n ${ }^{\circ}$ 352/2007 de 23 de Outubro 2007; Vieira e Quintero, 2008).

As lesões dentárias são lesões corporais e, neste âmbito, são consideradas nos Códigos Penal (Código Penal. Decreto-Lei n ${ }^{\circ} 2.848$, de 07 de Dezembro de 1940) e Civil (Código Civil. Lei $\mathrm{n}^{\circ}$ 10.406, de 10-01-2002) brasileiros. A desvalorização do sistema estomatognático e principalmente do órgão dentário é um fator cultural brasileiro, enquanto nos países europeus o dente é valorizado como um órgão anatômico e funcional. Salientamos que na tabela brasileira de Invalidez Total ou Parcial por Acidente (Susep), na falta de indicação da percentagem de redução e sendo informado apenas o grau dessa redução (máximo, médio ou mínimo), a indenização é calculada, respectivamente, utilizando-se $75 \%, 50 \%$ e $25 \%$ do valor atribuído pela tabela a uma determinada sequela. A omissão de detalhes permite a permissividade na interpretação individual (Corte-Real, 2003; 2009).

Em contrapartida, de acordo com a Tabela Nacional de Avaliação de Incapacidades Permanentes em Direito Civil (Decreto-Lei no 352/2007 de 
23 de Outubro 2007), é valorizada a perda do órgão dentário bem como o seu tipo de reabilitação, que reduz o valor da incapacidade em $50 \%$ com a utilização de próteses removíveis e em $75 \%$ com próteses fixas. Contudo, para a reabilitação por implantes, a avaliação pela tabela encontra-se confusa, sendo considerado 1 a 3 pontos para cada grupo de implantes (Corte-Real, 2003; 2009).

Uma prótese fixa, corretamente executada e bem adaptada, corrige quase completamente as funções estética, mastigatória e fonética. Por outro lado, deve-se levar em conta a vida média da prótese usada, para informar no relatório o número de previsíveis renovações e seu custo (Magalhães, 1998).

$\mathrm{O}$ fator de coeficiente de antagonismo, considerado por alguns autores, atua como fator corretor da função mastigatória. Baseia-se na idéia de que deve-se ressarcir a perda de função mastigatória do dente antagonista ao dente realmente perdido, dobrando-se o valor mastigatório do dente perdido (Pérez, Garrido et al., 1996; Souza, 2006).

Consideramos necessário que os valores atribuídos em qualquer tabela a uma sequela sejam atualizados de forma a acompanhar a evolução tecnológica e os respectivos tratamentos (Corte-Real, 2003; 2009).

\section{MATERIAL E MÉTODOS}

A amostra foi composta por 150 profissionais, divididos em: 50 advogados, 50 médicos e 50 médicos dentistas. Foram obtidos os consentimentos deste estudo por cada um dos intervenientes (anexo 3). A amostra analisada compreendeu praticamente a mesma faixa etária nos três grupos, estando médicos entre 27 a 74 anos, advogados entre 22 e 60 e médicos dentistas entre 22 e 69 . Em relação aos médicos, 28 eram do sexo masculino e 22 do sexo feminino; nos advogados, 31 eram do sexo masculino e 19 do sexo feminino; nos médicos dentistas, 27 eram do sexo masculino e 23 do sexo feminino (tabela 1).

Tabela 1 - Faixa etária e sexo nos três grupos profissionais

\begin{tabular}{c|ccc}
\hline Grupos Profissionais & Idade & Sexo \\
\hline \multirow{2}{*}{ Médicos } & 27 a74 anos & 28 & Feminino \\
Advogados & 22 a 60 anos & 31 & 22 \\
Médicos Dentistas & 22 a 69 anos & 27 & 19 \\
\hline
\end{tabular}


A seleção da amostra foi realizada de maneira aleatória. Os questionários foram estregues no trabalho das pessoas que integraram a amostra selecionada: os profissionais da área jurídica foram procurados em escritório de advocacia; os da área médica no Hospital Universitário da Universidade de São Paulo; os da área odontológica na FUNDECTO (Fundação para o Desenvolvimento Científico e Técnico da Odontologia), instituições localizadas na cidade de São Paulo.

Os entrevistados receberam um protocolo composto pelo capítulo de Estomatologia da Tabela Nacional de Avaliação de Incapacidades Permanentes em Direito Civil (Decreto-Lei no 352/2007 de 23 de Outubro 2007) e um questionário com seis perguntas, versando sobre sua aplicação (anexo 2). Todos os entrevistados tinham conhecimento da Tabela de Invalidez Total ou Parcial por Acidente (Susep) (anexo1).

Foram colocadas seis questões objetivas, para as quais os entrevistados tinham que assinalar uma única resposta perante três alternativas: sim, não ou não sabe. As questões colocadas pretenderam avaliar o conhecimento (Questão 1: A referida tabela é de seu conhecimento?) (gráfico 1), a experiência (Questão 2 - Possui experiência na avaliação de lesões causadas por traumatismo odontológico e de face?) (gráfico 2), a adequação das sequelas (Questão3 - Considera adequados os valores atribuídos pela tabela às seqüelas odontológicas?) (gráfico 3) e respectivas pontuações (Questão 4 - Considera que as lesões contempladas pela tabela são suficientes para avaliação do dano odontológico?) (gráfico 4). Questiona-se, ainda, a introdução de uma tabela de avaliação médico-legal na prática pericial brasileira (Questão 5 - Acredita que a tabela facilitaria a quantificação e o entendimento da avaliação do dano no âmbito Civil? e Questão 6 - Acredita ser possível a aplicação desta metodologia nas perícias realizadas no Brasil?).

Todos os entrevistados responderam às mesmas questões, com exceção dos advogados, que não responderam à questão dois.

Este protocolo foi aprovado pelo Comitê de Ética em Pesquisa da Faculdade de Odontologia da Universidade de São Paulo, CAAE 009.0.017.000-10.

Foi efetuada a análise matemática e a respectiva representação gráfica dos resultados no programa Microsoft Office Excel 2007.

\section{RESULTADOS}

Os resultados apresentados pelas questões de um a seis estão demonstrados nos gráficos abaixo. O gráfico 1 representa as respostas de médicos, advogados e médicos dentistas à questão 1 (A referida tabela é de seu conhecimento?). O gráfico 2 representa as respostas de médico e médicos dentistas à questão 
2 (Possui experiência na avaliação de lesões causadas por traumatismo odontológico e de face?). Da mesma forma, as respostas dos três grupos profissionais às questões 3 (Considera adequados os valores atribuídos pela tabela às seqüelas odontológicas?), 4 (Considera que as lesões contempladas pela tabela são suficientes para avaliação do dano odontológico?), 5 (Acredita que a tabela facilitaria a quantificação e o entendimento da avaliação do dano no âmbito Civil?) e 6 (Acredita ser possível a aplicação desta metodologia nas perícias realizadas no Brasil?) estão descritas nos gráficos 3, 4, 5 e 6, respectivamente.

Gráfico 1 - Respostas de médicos, advogados e dentistas à questão 1 sobre o conhecimento a respeito da Tabela Nacional para Avaliação de Incapacidades Permanentes em Direito Civil (questão 1)

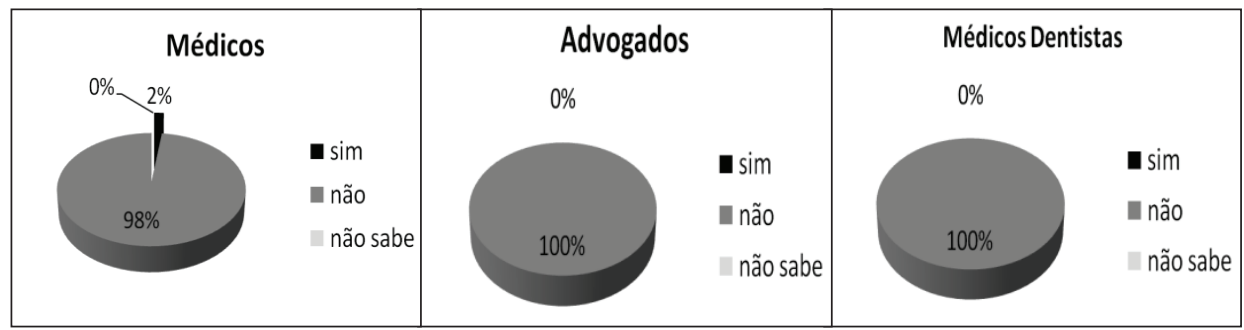

Gráfico 2 - Respostas de médicos e médicos dentistas quando abordados sobre sua experiência na avaliação de lesões causadas por traumatismo odontológico e da face.

Essa pergunta não foi feita a advogados (questão 2)

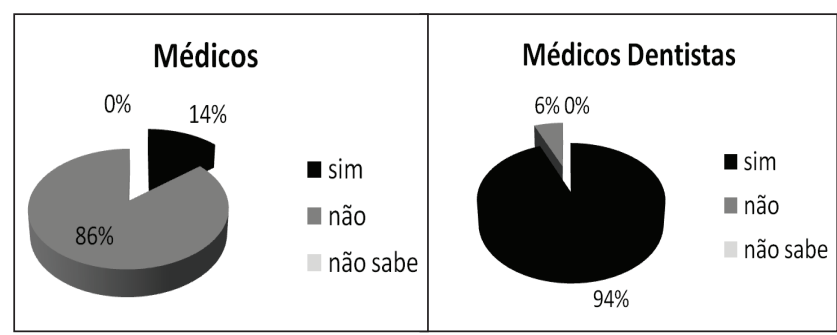

Gráfico 3 - Respostas de médicos, advogados e médicos dentistas quando perguntados se consideram adequados os valores atribuídos a cada seqüela (questão 3)

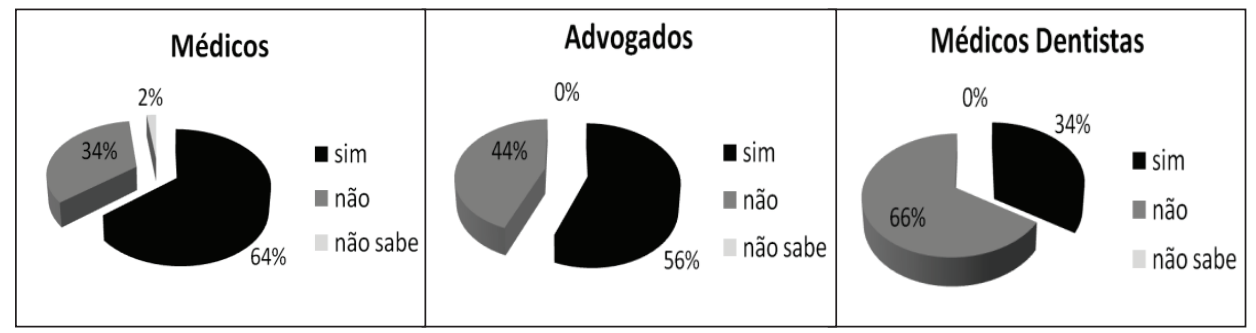


Gráfico 4 - Respostas de médicos, advogados e médicos dentistas quando perguntados se as lesões contempladas pela tabela são suficientes para avaliação do dano odontológico (questão 4)

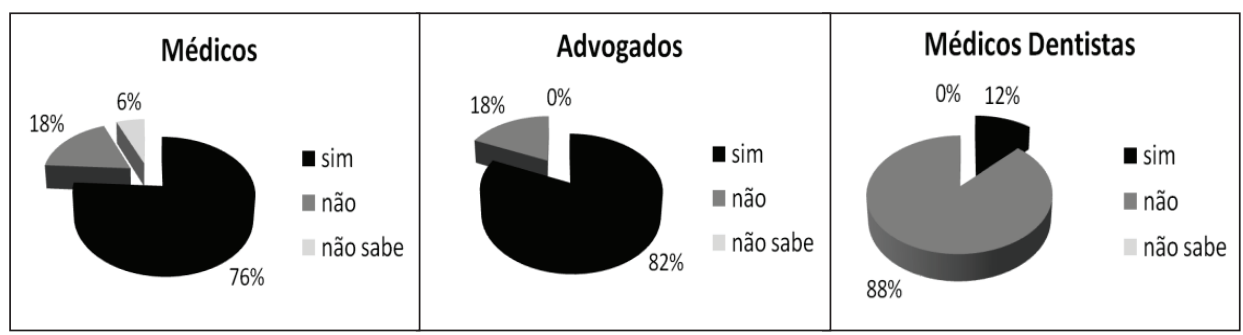

Gráfico 5 - Respostas de médicos, advogados e médicos dentistas quando perguntados se acreditam que a tabela facilitaria a quantificação e o entendimento da avaliação do dano no âmbito Civil (questão 5)

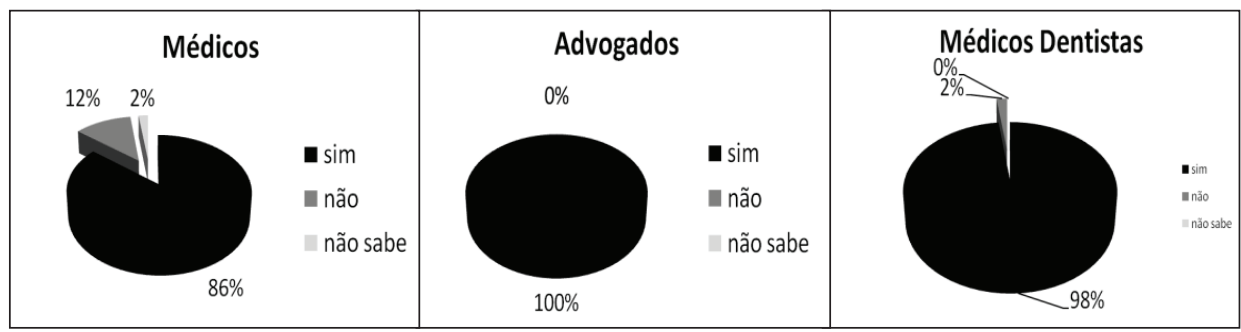

Gráfico 6 - Respostas de médicos, advogados e médicos dentistas quando perguntados se acreditam ser possível a aplicação desta metodologia nas perícias realizadas no Brasil (questão 6)

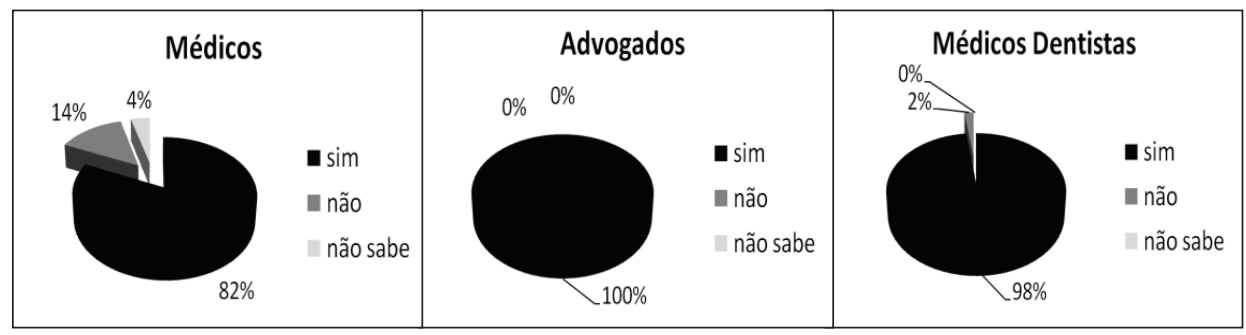

\section{DISCUSSÃO}

Atualmente, a avaliação do dano à integridade corporal adquiriu uma particular relevância pela sua repercussão econômica e social. O resultado da evolução tecnológica e da preocupação ressarcitória pelo dano causado à vítima exigiu a uniformização de critérios para uma melhor orientação médico-legal (Magalhães, 1998; Magalhães e Pinto da Costa, 2007). 
Neste estudo escolhemos três grupos profissionais: médicos, advogados e médicos dentistas, cujas áreas do conhecimento estão intimamente relacionadas com a peritagem e a avaliação médico-legal do dano corporal. Escolhemos uma faixa etária de 22 aos 74 anos, correspondendo a uma população ativa e capaz de cumprir os objetivos acima expostos. Deste modo, pretendemos analisar o conhecimento dos participantes brasileiros em relação à existência, aplicabilidade e utilidade de uma tabela normativa e orientativa da valorização do dano em Portugal, designada por Tabela Nacional de Avaliação de Incapacidades Permanentes em Direito Civil, publicada conjuntamente com a última atualização da Tabela Nacional de Incapacidades por Acidentes de Trabalho ou Doenças Profissionais (Decreto Lei $n^{\circ}$ 352/2007 de 23 de Outubro 2007).

Os resultados obtidos em relação à questão 1 (A referida tabela é de seu conhecimento?), representados pelo gráfico 1, indicam que apenas $2 \%$ dos médicos entrevistados relatou conhecimento a respeito da tabela utilizada em Portugal. A totalidade de advogados e médicos dentistas relatam não terem nenhum conhecimento sobre a referida tabela.

A avaliação do dano corporal tem por objetivo a determinação de um valor de incapacidade que se traduz na fixação de uma indemnização material para a reparação da perda de capacidade inerente a um acontecimento. A existência de uma tabela que expressa, para cada perda de capacidade, um intervalo numérico a atribuir pelo perito médico, constitui um importante passo de uniformização de critérios para avaliação do dano no domínio da responsabilidade civil (Vieira e Quintero, 2008). Existem, contudo, parâmetros que requerem uma avaliação qualitativa que podem ajustar o valor final atribuído pelo perito, no limite de cada intervalo. A atribuição de um valor final indemnizatório resulta da avaliação e discussão médico-legal (entre médicos e advogados) (Corte-Real, 2003).

Os resultados obtidos em relação à questão 2 (Possui experiência na avaliação de lesões causadas por traumatismo odontológico e de face?), representados pelo gráfico 2 , demonstram a inexperiência dos médicos brasileiros em relação à avaliação deste tipo de injúria, já que $86 \%$ responderam não, enquanto $94 \%$ dos médicos dentistas responderam sim.

Salientamos que a tabela portuguesa está dividida em capítulos e estes em subcapítulos, de acordo com as especialidades e subespecialidades médicas. A respectiva avaliação do dano corporal deve ser realizada por profissional apto, ou seja, aos médicos dentistas deve ser solicitada a avaliação no âmbito médico dentário. A frequência das ocorrências de sequelas neste campo médico pode justificar o aumento de solicitações deste tipo de avaliação (Vieira e Quintero, 2008; Corte-Real, 2009). 
Os resultados obtidos em relação à questão 3 (Considera adequados os valores atribuídos pela tabela às seqüelas odontológicas?), representados pelo gráfico 3 , indicam que os valores atribuídos pela tabela foram considerados adequados por $64 \%$ dos médicos e por $56 \%$ dos advogados, mas insuficientes por $66 \%$ dos médicos dentistas. É a partir da visão de corpo como uma expressão, principalmente, de totalidade, que a avaliação do dano deve ser estabelecida (Magalhães, 1998).

Os padrões culturais e costumes de cada sociedade influenciam as valorizações dos órgãos biológicos em diferentes níveis de percepção. Estas diferenças culturais relativas à valorização do corpo interferem, fortemente, no resultado da avaliação das sequlelas pós-traumáticas (Corte-Real, 2003).

A evolução tecnológica em termos de tratamentos odontológicos deve ser acompanhada para que os valores atribuídos às seqüelas contempladas sejam atualizados (Corte-Real, 2009).

Os resultados obtidos em relação à questão 4 (Considera que as lesões contempladas pela tabela são suficientes para avaliação do dano odontológico?), estão representados pelo gráfico 4 . Enquanto $76 \%$ dos médicos e $82 \%$ dos advogados acreditam que as sequelas descritas na tabela são suficientes para uma correta avaliação do dano odontológico, 88\% dos médicos dentistas consideram-nas insuficientes, reforçando a necessidade de uma tabela mais abrangente e específico para a realidade das perícias odontológicas brasileiras.

A perda do órgão dentário e suas respectivas correções por próteses, a perturbação pós-traumática da oclusão dentária ou da articulação têmporo mandibular, em que se salienta a limitação da abertura bucal e a amputação da parte móvel da língua, são as seqüelas atribuídas pela Tabela Nacional de Avaliação de Incapacidades Permanentes em Direito Civil (Decreto-Lei ${ }^{\circ}$ 352/2007 de 23 de Outubro 2007). Pelo exposto, consideramos ser necessário a execução de mais estudos neste âmbito que podem complementar estes tipos de seqüela bem como uma reabilitação diferenciada. Consideramos que uma reabilitação fixa , corretamente executada e bem adaptada, corrige quase completamente as funções estética, mastigatória e fonética; não deixando de salientar a vida média referida reabilitação que deve constar no relatório para previsíveis renovações (Cardozo, 1994; Magalhães, 1998; Corte-Real, 2009).

Os resultados obtidos em relação à questão 5 (Acredita que a tabela facilitaria a quantificação e o entendimento da avaliação do dano no âmbito Civil?), representados pelo gráfico 5 , indicam que médicos, advogados e médicos dentistas, com 86\%, 100\%, 98\% de respostas afirmativas, respectivamente, acreditam que o uso de tabelas facilitaria a quantificação e o entendimento da avaliação do dano no âmbito civil, o que fundamenta a elaboração deste estudo. 
Da mesma forma, os resultados obtidos em relação à questão 6 (Acredita ser possível a aplicação desta metodologia nas perícias realizadas no Brasil?), representados pelo gráfico 5 , confirmam a ideia de que seria possível ou, no mínimo, aceitável a aplicação desta metodologia nas perícias realizadas no Brasil, com resposta positiva de $82 \%$ dos médicos, $100 \%$ dos advogados e $98 \%$ dos médicos dentistas. Pelo exposto, consideramos que o nosso estudo poderá ser complementado no sentido de viabilizar a aplicação de uma tabela idêntica à tabela portuguesa no Brasil.

\section{CONCLUSÕES}

1. O uso de tabelas para quantificação do dano corporal pós-traumático é elemento pouco difundido entre médicos, advogados e médicos dentistas brasileiros.

2. A avaliação dos traumatismos odontológicos e de face deve ser feita por médicos dentistas.

3. Existe a necessidade de elaboração de uma tabela mais abrangente e específica para a realidade das perícias brasileiras, pois a sua aplicação facilitaria a quantificação e o entendimento da avaliação do dano no âmbito civil.

4. Existe uma boa aceitação da aplicação desta metodologia de avaliação do dano corporal entre médicos, advogados e médicos dentistas, para as perícias realizadas no Brasil.

5. A Tabela Portuguesa de Avaliação de Incapacidades Permanentes em Direito Civil (Decreto-Lei no 352/2007 de 23 de Outubro 2007) quantifica, de forma aceitável, as sequelas do sistema estomatognático, reforçando-se assim a necessidade de revisão da atual legislação securitária brasileira, no sentido de a aproximar à realidade portuguesa.

\section{REFERÊNCIAS BIBLIOGRÁFICAS}

CALDAS, I. et al. Orofacial damage resulting from road accidents. Dental Traumatology, v. 24, p. 410-415, 2008.

CARDOZO, H. Avaliação das lesões dentárias em âmbito civil e a atuação do cirurgião-dentista. Rev Odontologia Univ São Paulo, v. 6, n. 1, p. 45-66, 1994. 
CORTE-REAL, A. T. D. C. M. Considerações na avaliação do dano nos traumatismos faciais por reabilitação protética implanto-suportada - uma perspectiva em direito civil Portugal: $2^{\circ}$ Congresso Nacional de Medicina Legal 2003.

CORTE-REAL, A. T. D. C. M. Curso da Nobel e Astra Tech Formação Contínua em Implantologia. Temas de avaliação médico legal no âmbito da implantologia. Portugal: Faculdade de Medicina Departamento de Medicina Dentária da Universidade de Coimbra 2009.

Código Civil. Lei n 10.406, de 10-01-2002. Brasil 2002.

Código Penal. Decreto-Lei no 2.848, de 07 de dezembro de 1940. Brasil 1940.

Decreto-Lei n ${ }^{\circ} 352 / 2007$ de 23 de Outubro 1. ${ }^{a}$ série - N $^{\circ} 204$. Portugal: Diário da República 2007.

MAGALHÃES, T. Estudo tridimensional do dano corporal: lesão função e situação.Sua aplicação médico-legal. Coimbra: Almedina, 1998.

MAGALHÃES, T.; PINTO DA COSTA, D. Avaliação do dano na pessoa em sede de Direito Civil. Perspectivas actuais. Revista da Faculdade de Direito da Universidade do Porto, v. 4, p. 419-452, 2007.

PÉREZ, B.; GARRIDO, B.; SÁNCHEZ, J. Metodología para la valoración del daño bucodental. Madrid: Editorial Mapfre Medicina, 1996.

SOUZA, A. Verificação do grau de perda estética em alterações faciais. 2006. (dissertação). Faculdade de Odontologia, Universidade de São Paulo, São Paulo.

SUSEP. Circular N ${ }^{\circ}$ 302, de 19 de setembro de 2005. p. http://www.susep.gov.br, Acesso em: 10 de Novembro.

VIEIRA, D.; QUINTERO, J. Aspectos práticos da avaliação do dano corporal em Direito Civil. Coimbra: Biblioteca Seguros, 2008. ISBN 9898074310.

\section{ANEXO 1}

Tabela de Invalidez Permanente Total ou Parcial por Acidente

\section{Total}

Perda da visão de ambos os olhos

Perda total do uso de ambos os membros superiores

$100 \%$

Perda total do uso de ambos os membros inferiores

$100 \%$

Perda total do uso de ambos as mãos

$100 \%$

Perda total do uso de um membro superior e um membro inferior

$100 \%$

Perda total do uso de uma das mãos e de um dos pés

$100 \%$

Perda total do uso de ambos os pés

$100 \%$

Alienação mental incurável

$100 \%$ 


\section{Parcial - Diversos}

Perda total da visão de um olho $\quad 30 \%$

Perda total da visão de um olho, quando o Segurado já não tiver a outra vista $\quad 70 \%$

Surdez total e incurável de ambos os ouvidos $\quad 40 \%$

Surdez total e incurável de um dos ouvidos $\quad 20 \%$

Mudez incurável $\quad 50 \%$

Fratura não consolidada do maxilar inferior $\quad 20 \%$

Imobilidade do segmento cervical da coluna vertebral $20 \%$

Imobilidade do segmento tóraco-lombo-sacro da coluna vertebral $\quad 25 \%$

\section{Parcial - Membros Superiores}

$\begin{array}{ll}\text { Perda total do uso de um dos membros superiores } & 70 \%\end{array}$

$\begin{array}{ll}\text { Perda total do uso de uma das mãos } & 60 \%\end{array}$

$\begin{array}{ll}\text { Fratura não consolidada de um dos úmeros } & 50 \%\end{array}$

Fratura não consolidada de um dos segmentos rádio-ulnares $\quad 30 \%$

Anquilose total de um dos ombros $\quad 25 \%$

Anquilose total de um dos cotovelos $\quad 25 \%$

Anquilose total de um dos punhos $\quad 20 \%$

Perda total do uso de um dos polegares, inclusive o metacarpiano 25\%

Perda total do uso de um dos polegares, exclusive o metacarpiano $\quad 18 \%$

$\begin{array}{ll}\text { Perda total do uso da falange digital do polegar } & 09 \%\end{array}$

Perda total do uso de um dos dedos indicadores $\quad 15 \%$

Perda total do uso de um dos dedos mínimos ou um dos dedos médios $\quad 12 \%$

Perda total do uso de um dos dedos médios ou de um dos dedos anulares $\quad 09 \%$

Perda total do uso de qualquer falange, exclusive as do polegar $\quad 1 / 3$ do valor do dedo

\section{Parcial - Membros Inferiores}

$\begin{array}{ll}\text { Perda total do uso de um dos membros inferiores } & 70 \%\end{array}$

Perda total do uso de um dos pés $\quad 50 \%$

$\begin{array}{ll}\text { Fratura não consolidada de femur } & 50 \%\end{array}$

Fratura não consolidada de uma dos segmentos tíbio-peroneiros $\quad 25 \%$

$\begin{array}{ll}\text { Fratura não consolidada da rótula } & 20 \%\end{array}$

Fratura não consolidada de um pé $\quad 20 \%$

Anquilose total de um dos joelhos $\quad 20 \%$

Anquilose total de um dos tornozelos $\quad 20 \%$

Anquilose total de um quadril $\quad 20 \%$

Perda parcial de um dos pés, isto é, perda de todos os dedos de uma parte do $\quad 25 \%$ mesmo pé

$\begin{array}{ll}\text { Amputação do } 1^{\circ} \text { ( primeiro ) dedo } & 10 \% \\ \text { Amputação de qualquer outro dedo } & 03 \%\end{array}$

Perda total do uso de uma falange do $1^{\circ}$ dedor respectivo 
Perda total do uso dos demais dedos

\section{Perda total do uso dos demais dedos} respectivo dedo

Encurtamento de um dos membros inferiores de 5 (cinco) centímetros ou mais $\quad 15 \%$ Encurtamento de um dos membros inferiores de 4 (quatro) centímetros 10\% Encurtamento de um dos membros inferiores de 3 (três) centímetros 06\% Encurtamento de um dos membros inferiores de menos de 3 (três) centímetros $\quad 0 \%$

\section{ANEXO 2}

\section{Protocolo do(a) entrevistado(a)}

Idade:

Sexo:

Profissão:

Tabela Nacional de Avaliação de Incapacidades Permanentes em Direito Civil

\begin{tabular}{|c|c|}
\hline \multicolumn{2}{|l|}{ Estomatologia } \\
\hline $\begin{array}{l}\text { Edentação completa insusceptível de correção por prótese } \\
\text { (atendendo à repercussão sobre o estado geral) }\end{array}$ & 20 a 28 \\
\hline $\begin{array}{l}\text { Perda de dente insusceptível de correção por prótese: } \\
\text { Incisivo ou canino } \\
\text { Premolar ou molar }\end{array}$ & $\begin{array}{r}1 \\
1,5\end{array}$ \\
\hline Disfunções mandibulares & 21 a 30 \\
\hline $\begin{array}{l}\text { Limitação da abertura bucal igual ou inferior a } 10 \mathrm{~mm} \\
\text { Limitação da abertura bucal entre } 10 \text { a } 30 \mathrm{~mm} \\
\text { Limitação da abertura entre } 31 \text { e } 40 \mathrm{~mm} \\
\text { (atendendo à bilateralidade, fenômenos dolorosos e perturbação da função) }\end{array}$ & 6 a 20 \\
\hline $\begin{array}{l}\text { Perturbação pós-traumática da oclusão dentária ou da articulação têmporo } \\
\text { mandibular } \\
\text { (segundo a repercussão sobre a mastigação, a fonação e as algias) }\end{array}$ & 2 a 10 \\
\hline $\begin{array}{l}\text { Amputação da parte móvel da língua } \\
\text { (tendo em consideração a repercussão sobre a palavra, a mastigação e a } \\
\text { deglutição,segundo a importância das perturbações) }\end{array}$ & 3 a 30 \\
\hline
\end{tabular}

\section{Sobre a tabela acima, responda as seguintes questões:}

Questão 1: A referida tabela é de seu conhecimento?
( )Sim
( )Não
( )Não sabe 
Questão 2 - Possui experiência na avaliação de lesões causadas por traumatismo odontológico e de face? (Apenas para médicos e médicos dentistas)

( ) Sim ( )Não ( )Não sabe

Questão 3 - Considera adequados os valores atribuídos pela tabela às seqüelas odontológicas?

( ) Sim ( )Não ( )Não sabe

Questão 4 - Considera que as lesões contempladas pela tabela são suficientes para avaliação do dano odontológico?

( )Sim ( )Não ( )Não sabe

Questão 5 - Acredita que a tabela facilitaria a quantificação e o entendimento da avaliação do dano no âmbito Civil?

( ) Sim ( )Não ( )Não sabe

Questão 6 - Acredita ser possível a aplicação desta metodologia nas perícias realizadas no Brasil?

( ) Sim ( )Não ( )Não sabe

\section{ANEXO 3}

Termo de consentimento livre e esclarecido do(a) entrevistado(a)

Estamos convidando a participar da pesquisa intitulada Utilização de tabelas como referência na avaliação do dano corporal- análise de três grupos profissionais brasileiros, parte da tese de doutorado em Ciências Odontológicas (área de concentração: Odontologia Legal) da Cirurgiã-Dentista CAROLINA BURNI VERÇOSA; sob orientação do Prof. Dr. RODOLFO FRANCISCO HALTENHOFF MELANI (Faculdade de Odontologia da Universidade de São Paulo) cujo objetivo é investigar como os profissionais da área jurídica - advogados, promotores e juízes -, médicos e médicos dentistas da cidade de São Paulo avaliam a "Tabela de Avaliação de Incapacidades Permanentes em Direito Civil”. Este protocolo, preenchido na íntegra ou em parte, poderá constar de publicações, uma vez que os pesquisadores garantem que o sigilo de sua identidade será preservado em qualquer situação. Caso aceite, sua participação consistirá apenas em responder ao questionário em anexo, o que 
trará maior conhecimento sobre o tema, sem benefício direto para você. Por se tratar apenas de um questionário, não apresenta riscos ou desconforto.

O questionário a ser preenchido nesta data será utilizado única e exclusivamente para a pesquisa: Utilização de tabelas como referência na avaliação do dano corporal-análise de três grupos profissionais brasileiros. As informações fornecidas por você serão confidenciais e de conhecimento apenas dos pesquisadores responsáveis. Os sujeitos da pesquisa não serão identificados em nenhum momento, mesmo quando os resultados desta pesquisa forem divulgados em qualquer forma.

Sua participação nesta pesquisa é voluntária, não havendo qualquer tipo de pagamento ou ônus referente a ela.

Você poderá se retirar desta pesquisa a qualquer momento, inclusive vetando a utilização deste protocolo sem que sofra nenhuma penalização. Os pesquisadores se comprometem a te informar sobre o andamento do trabalho sempre que solicitado, independentemente de continuar ou não colaborando com o estudo.

Após ler estas informações e de ter minhas dúvidas suficientemente esclarecidas pelo pesquisador, concordo em participar de forma voluntária neste estudo. Além disso, estou recebendo uma cópia deste termo.

de de

(nome por extenso do sujeito da pesquisa e RG)

(assinatura do sujeito da pesquisa)

(endereço e telefone para contato do sujeito da pesquisa)

Carolina Burni Verçosa

CRO/MG 32740

Doutoranda em Ciências Odontológicas

(Área de concentração: Odontologia Legal)
Prof. Dr. Rodolfo Francisco Haltenhoff Melani CRO/SP 26541

Departamento de Odontologia Legal

Faculdade de Odontologia da Universidade de São Paulo 
Caso tenha dúvidas sobre aspectos metodológicos da pesquisa, favor entrar em contato com o responsável Prof. Dr. Rodolfo Francisco Haltenhoff Melani pelo email rfmelani@usp.br (11) 3091789.

Caso tenha dúvidas sobre aspectos éticos da pesquisa, favor entrar em contato com o Comitê de Ética em Pesquisa (Av. Lineu Prestes 2227, 05508000) pelo email cepfo@usp.br .

Resumo: Utilização de tabelas como referência na avaliação do dano corporal. Análise de três grupos profissionais brasileiros

A utilização de tabelas como referência para avaliação do dano corporal, em várias vertentes do direito: civil, penal e trabalho, é o elemento essencial no estabelecimento da uniformidade de critérios que possibilitam a clareza no entendimento entre peritos e juristas. Embora exista uma tabela utilizada no Brasil, “Tabela de Invalidez Total ou Parcial por Acidente", essa não contempla plenamente todos os possíveis danos que podem envolver o campo odontológico, se comparada com a "Tabela Nacional de Avaliação de Incapacidades Permanentes em Direito Civil", utilizada em Portugal, que considera um número maior de sequelas. Neste trabalho, pretende-se avaliar a necessidade de sistematização da avaliação dos danos corporais, no âmbito de uma apreciação odontológica englobada numa avaliação médico-legal, bem como o conhecimento, a experiência, a adequação das sequelas e respectivas pontuações, junto dos médicos, advogados e médicos dentistas. Questionamos, por fim, a introdução de uma tabela de avaliação médico-legal na prática pericial brasileira. A amostra foi composta por 150 profissionais do Brasil, divididos em: 50 advogados, 50 médicos e 50 médicos dentistas, que receberam um exemplar do capítulo de Estomatologia da tabela utilizada em Portugal e um questionário com seis perguntas, versando sobre sua aplicação. Do nosso trabalho concluímos que o uso de tabelas para quantificação do dano corporal pós-traumático é elemento pouco difundido entre médicos, advogados e médicos dentistas; a avaliação dos traumatismos odontológicos e de face deve ser feita por médicos dentistas; existe a necessidade de elaboração de uma tabela mais abrangente e específica para a realidade das perícias brasileiras, pois a sua aplicação facilitaria a quantificação e o entendimento da avaliação do dano no âmbito civil; existe uma boa aceitação da aplicação desta metodologia de avaliação do dano corporal entre médicos, advogados e médicos dentistas, nas perícias realizadas no Brasil.

Palavras-Chave: Odontologia legal; avaliação do dano; tabela.

Summary: The use of tables as a reference in the bodily injury assessment. Analysis of three Brazilian professional groups

The use of tables as a reference for evaluation of body damage in various aspects of law: civil, penal and labor, is the essential element in the establishment of uniform criterion that enables clarity of understanding between experts and lawyers. Although there is a table used in Brazil, "Table of Total or Partial Disability due to Accident," this does not 
address fully all the possible damage that may involve the dental field, compared to the "Table of the National Assessment of permanent disability in Civil Law", used in Portugal, which considers a larger number of sequels. In this work, we intend to evaluate the need for systematic evaluation of injuries, as part of a dental examination encompassed a medicolegal assessment, as well as knowledge, experience, adequacy of sequel and their scores, with doctors, lawyers and dentists. We question, finally, the introduction of an evaluation table medical-legal expert in Brazilian practice. The sample consisted of 150 professionals from Brazil, divided into 50 lawyers, 50 doctors and 50 dentists, who received a copy of the chapter of Stomatology of the table used in Portugal and a questionnaire with six questions, dealing with your application. From our work we conclude that the use of tables for the quantification of post-traumatic bodily harm element is not widespread among doctors, lawyers and dentists, assessment of dental and facial trauma must be made by dentists, there is a need to prepare a table more comprehensive and specific expertise to the reality of Brazil, since its implementation would facilitate the quantification and understanding of the assessment of damages in civil there is good acceptance of the application of this methodology for evaluation of body damage among doctors, lawyers and dentists in skills performed in Brazil.

Key-words: Forensic dentistry; damage assessment; table.

Pedido de separatas:

CAROLINA VERÇOSA

vercosacarol@gmail.com 